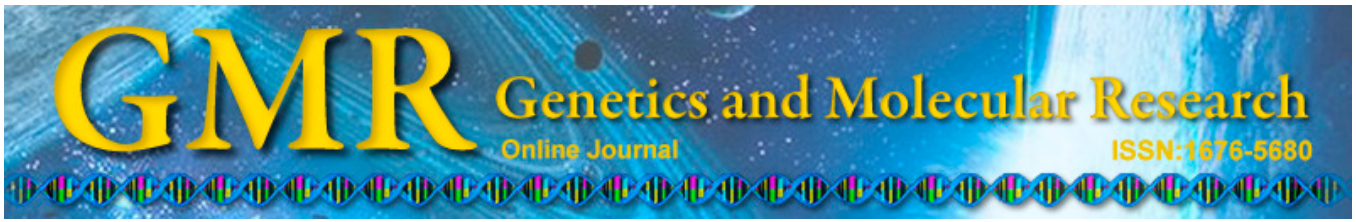

\title{
Cloning and transformation analysis of isoflavone synthase gene into Minshan Trifolium pratense
}

\author{
H.H. Hu ${ }^{1 *}$, C.Q. Jing ${ }^{2 *}$, R. Liu ${ }^{1}$, W.D. Li ${ }^{1}$ and H.G. Feng ${ }^{2}$ \\ ${ }^{1}$ College of Life Science and Technology, Sanquan School, \\ Xinxiang Medical University, Xinxiang, China \\ ${ }^{2}$ College of Life Science and Technology, Xinxiang Medical University, \\ Xinxiang, China \\ *These authors contributed equally to this study. \\ Corresponding author: H.G. Feng \\ E-mail: fenghuigen@126.com
}

Genet. Mol. Res. 14 (3): 9291-9297 (2015)

Received November 13, 2014

Accepted March 26, 2015

Published August 10, 2015

DOI http://dx.doi.org/10.4238/2015.August.10.9

\begin{abstract}
The aim of this study was to clone the isoflavone synthase (IFS) gene and establish the recombinant Minshan Trifolium pratense. The IFS gene was cloned from the callus of Minshan T. pratense using reverse transcription-polymerase chain reaction. The plant expression vector $\mathrm{pRI101-AN-IFS} \mathrm{was} \mathrm{constructed} \mathrm{and} \mathrm{introduced} \mathrm{into}$ Agrobacterium tumefaciens strain LBA4404, and then screened under cephalosporin. IFS expression was detected by reverse transcriptionpolymerase chain reaction. The IFS gene was cloned successfully. Sequence analysis indicated that IFS gene had high homology with similar genes from other plants. The IFS-overexpressing callus was obtained by introducing the LBA4404-harboring IFS-pRI101-AN-IFS vector into $T$. pratense calluses.
\end{abstract}

Key words: Gene cloning; Isoflavone synthase; Sequence analysis; Callus; Trifolium pretense 


\section{INTRODUCTION}

Minshan Trifolium pratense or red clover is a well-known, high-yield grazing plant that has been cultivated for more than 60 years since its introduction by the Americans in 1944. Minshan T. pratense was considered one of Min County's best grass varieties for many years, was named by the National Feed Pasture Variety Approval Committee in 1987, and is considered the first grass variety in China (Wang et al., 2005).

Clover is used as an expectorant, analgesic, anti-bacterial, and anti-inflammatory medicinal plant in many countries and regions (Reiter et al., 2011). Previous studies reveal that clover contains high levels of isoflavones (Kagan and Flythe, 2012; Kaurinovic et al., 2012; Kolodziejczyk-Czepas, 2012; Kicel and Wolbiś, 2013). Clover isoflavones are the most studied phytoestrogens after soy isoflavones, and are considered to be healthy because of their biological and pharmacological uses (Sabudak and Guler, 2009). Clover isoflavones are currently used as dietary supplements to replace the function of hormones (Jung et al., 2000). Other studies have shown that clover isoflavones can also significantly reduce the spread of cancer cells (Lu and Gong, 1998; Villaseca, 2012).

Great progress has been achieved in understanding the biosynthetic pathway of isoflavones. Isoflavone synthase (ISF) is a key enzyme in the biosynthesis pathway of isoflavones as it catalyzes flavanones in the pathway (Overkamp et al., 2000; Liu et al., 2002). To obtain new T. pratense lines of high-yielding isoflavones, we cloned and introduced the IFS gene into T. pratense calluses.

\section{MATERIAL AND METHODS}

\section{Materials}

Minshan T. pratense seeds were stored in our lab. pGEM-T Easy and pRI101-AN, which were used for vector construction, were purchased from Promega (Madison, WI, USA) and Takara (Shiga, Japan), respectively. The host bacterium Escherichia coli DH5 $\alpha$ was provided by our laboratory.

\section{Preparation of explant culture}

The $T$. pratense seeds were washed in water for $20 \mathrm{~min}$ and then soaked for $1 \mathrm{~min}$ in $70 \%$ ethanol. After sterilizing for 20 to 30 min with $5 \%$ hypochlorous acid, the seeds were washed with sterile water 3 times. The seeds were then sown in Murashige and Skoog medium and were grown for 7 days in a growth chamber at $25^{\circ} \mathrm{C}$ and with a light/dark cycle of $16 / 8 \mathrm{~h}$.

The hypocotyl and cotyledon of $T$. pratense seedlings were cut into pieces and inoculated into Murashige and Skoog minimal medium containing $30 \mathrm{~g} / \mathrm{L}$ sugar, $2 \mathrm{mg} / \mathrm{L}$ 2,4-dichlorophenoxyacetic acid, and $0.5 \mathrm{mg} / \mathrm{L} 6$-benzylaminopurine. The hypocotyl and cotyledon were then cultured in the dark and observed once per week.

The induced callus was cultivated on Murashige and Skoog medium containing 30 $\mathrm{g} / \mathrm{L}$ sugar, $0.5 \mathrm{mg} / \mathrm{L}$ 6-benzylaminopurine, and $0.5 \mathrm{mg} / \mathrm{L}$ 2,4-dichlorophenoxyacetic acid, and was observed once per week. 


\section{Cloning of the IFS gene}

Primers were designed and synthesized based on the IFS sequences, including the upstream primer 5'-CCCGGATCCATGTTGTTAGAAATTGCAGTTGC-3' and the downstream primer 5'-GGCCTTAAGTTAAGAGGAAAGGAGTTTAGCTG-3' of ISF.

Total RNA was extracted from $100 \mathrm{mg}$ T. pratense callus using the RNAiso Plus kit according to manufacturer instructions (Invitrogen, Carlsbad, CA, USA). IFS sequences were cloned from $T$. pratense through reverse transcription-polymerase chain reaction (RT-PCR) under the following conditions: 10 cycles of $30 \mathrm{~s}$ denaturation at $94^{\circ} \mathrm{C}, 30 \mathrm{~s}$ annealing at $58^{\circ} \mathrm{C}$, $1.5 \mathrm{~min}$ amplification at $72^{\circ} \mathrm{C}, 25$ cycles of $30 \mathrm{~s}$ denaturation at $94^{\circ} \mathrm{C}, 30 \mathrm{~s}$ annealing at $52^{\circ} \mathrm{C}$, $1.5 \mathrm{~min}$ amplification at $72^{\circ} \mathrm{C}$, and $5 \mathrm{~min}$ amplification at $72^{\circ} \mathrm{C}$.

The PCR product was purified from the agarose gel using the Agarose Gel DNA Purification Kit (Takara) according to the manufacturer instructions. The purified IFS gene was subcloned into the pGEM-T Easy vector, and then transformed into E. coli. After screening with ampicillin-concentrated LB medium, isopropyl $\beta$-D-1-thiogalactopyranoside, and $\mathrm{X}$-gal and after detection with PCR, the bacterial colony-harboring target gene was further sequenced and named pGEM-IFS.

\section{Construction and transformation of expression vector}

The full-length isoflavone synthase cDNA inserted into the pGEM-T vector was digested with $B a m \mathrm{HI} / E c o$ RI and ligated into pRI101-AN.

The recombinant vector pRI101-AN-IFS was transformed into Agrobacterium LBA4404 using the freezing and thawing method, and was subsequently transformed into $T$. pratense callus.

\section{Explant transformation and detection}

The transformation was performed based on the method of Khanlou et al. (2011). The petioles of 7- to 10-day old $T$. pratense were cut into 5-mm pieces and pre-incubated for 3 days on B5 medium containing acetosyringone. The materials were then inoculated with an Agrobacterium-harboring target gene for $48 \mathrm{~h}$. After washing with sterile water, the materials were transferred to B5 medium containing $2 \mathrm{mg} / \mathrm{L}$ 2,4-dichlorophenoxyacetic acid, $2 \mathrm{mg} / \mathrm{L}$ naphthalene acetic acid, $2 \mathrm{mg} / \mathrm{L}$ kinetin, $75 \mathrm{mg} / \mathrm{L}$ kanamycin, and $250 \mathrm{mg} / \mathrm{L}$ cephalosporin, and grown in a growth chamber under a light/dark cycle of $8 / 16 \mathrm{~h}$ and a temperature of $25^{\circ} \mathrm{C}$ for 4 to 6 weeks. IFS expression in the callus-carrying IFS-Tp was detected by RT-PCR as described above. The primers used are as follows: P1, 5'-AGCGGCGATACCGTAAAGCACGA-3'; P2, 5'-RAAGGGACTGGCTGCTATTGGGC-3'.

\section{RESULTS}

\section{Establishing the callus culture system}

T. pratense leaves were cultured on induced medium. Traces of callus appeared on the incision site of the hypocotyledonary axis after 4 days. The leaves began to curl after 2 weeks. 
Numerous calluses appeared on the incision site. The explant-induced calluses exhibited excellent growth (Figure 1).

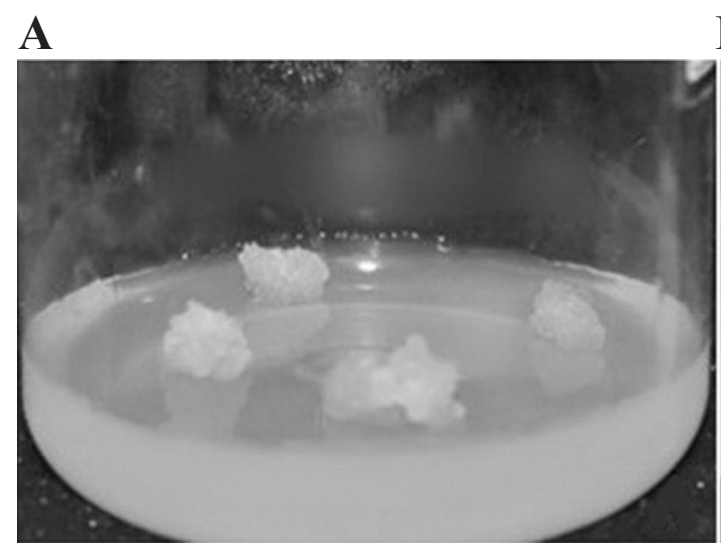

B

Figure 1. Calluses of cotyledon and hypocotyl.

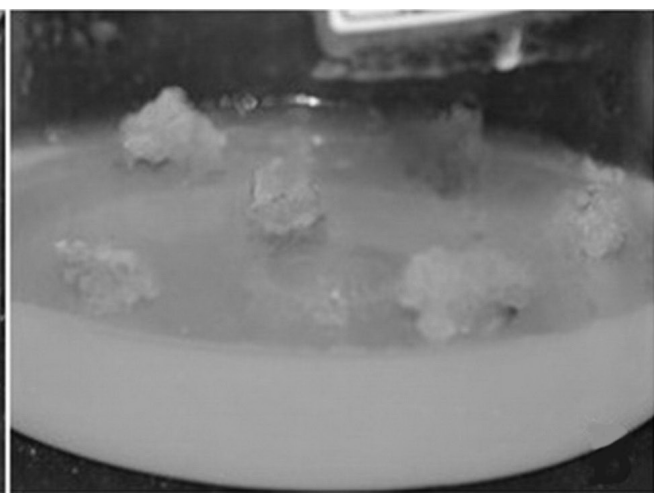

\section{Cloning of the IFS gene}

RT-PCR was used to clone the IFS gene using the primers designed based on the IFS gene sequence. A $1.5-\mathrm{kb}$ product was obtained (Figure $2 \mathrm{~A}$ ), which was similar to the size of the known IFS gene. This product was ligated into the pGEM vector and digested with EcoRI, which generated 3000- and 1500-bp products. The correct plasmid with EcoRI was used for sequence analysis (Figure 2B). Sequence analysis indicated that the full-length IFS cDNA contained a 1575 -bp open reading frame (525 amino acids) coding for a $59.1-\mathrm{kDa}$ protein. BLAST analysis showed $99 \%$ homology to T. pratense IFSs (AY253284.1). Identity at the amino acid level ranged from 75 to $80 \%$, whereas similarity ranged from 92 to $97 \%$. A high level of similarity (95 to $99 \%$ ) was observed among the IFSs of soybean, white clover, alfalfa, and mung bean.

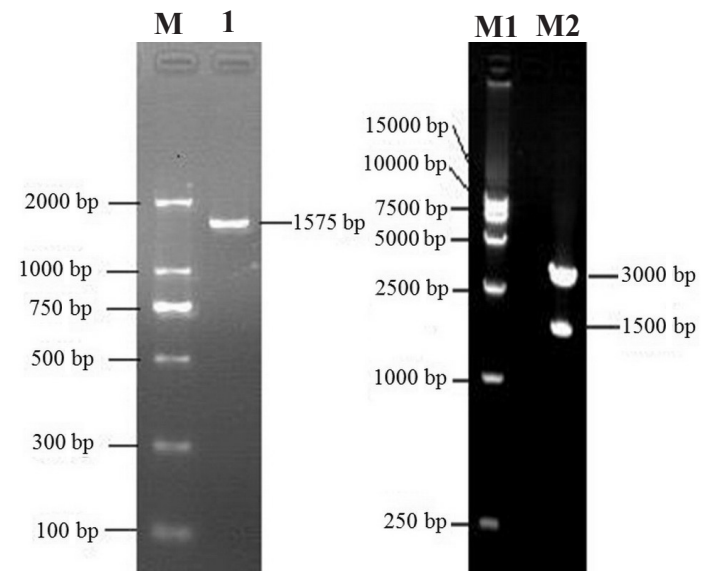

Figure 2. A. Products of PCR. B. Restriction and PCR amplification maps of recombinant plasmid. Lane $M=$ marker DL2000; lane 1 = product of PCR; lane M1 = marker DL10,000; lane M2 = pGEM-IFS plasmid EcoRI enzyme-digested product. 


\section{Construction and transformation of pRI101-AN-IFS plant}

The pRI101-AN-IFS plant expression vector was introduced into Agrobacterium LBA4404 by freezing and thawing. The clone containing the expression vector was screened on LB medium containing kanamycin and rifampicin (Figure 3). A fragment consistent with the expected results was obtained by PCR and digesting detection, and indicated that the pRI101-AN-IFS vector was successfully introduced into Agrobacterium LBA4404.

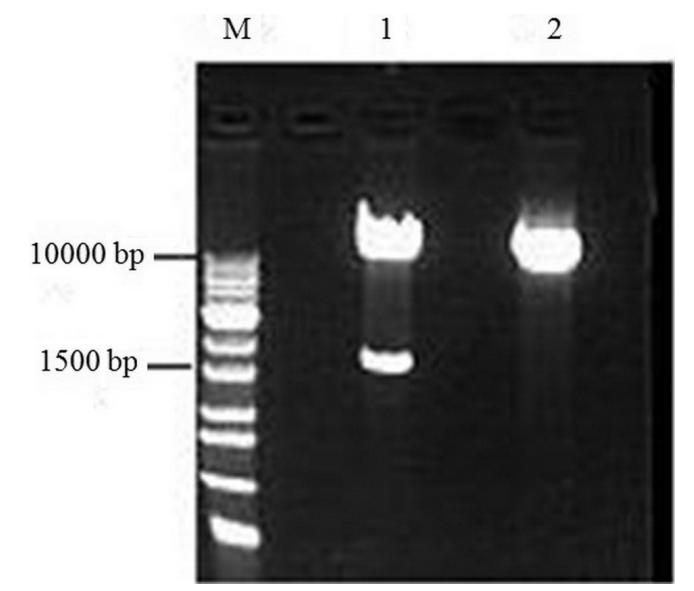

Figure 3. pRI 101-AN-IFS enzyme identification. Lane $M=$ DNA marker 10,000; lane $1=$ pRI 101-AN-IFS plasmid EcoRI enzyme-digested product; lane 2 = pRI101-AN-IFS plasmid; lane 3 = pRI 101-AN-IFS plasmid EcoRI enzyme-digested product.

\section{Transformation of Agrobacterium LBA4404 into T. pratense}

One hundred pieces of T. pratense inoculated with Agrobacterium LBA4404 were screened on a medium containing antibiotic. The inoculated petiole differentiated and showed more calluses after 2 weeks compared with that of the untreated petiole (Figure 4). The callus from the inoculated petiole exhibited good growth in the subsequent culture, but the callus from the untreated petiole showed no difference and gradually died.

RT-PCR was used to detect the IFS gene expression in the transformed callus (Figure 5). A 481-bp neomycin phosphotransferase II gene was obtained, indicating that the IFS gene was transformed into the T. pratense callus and was expressed.

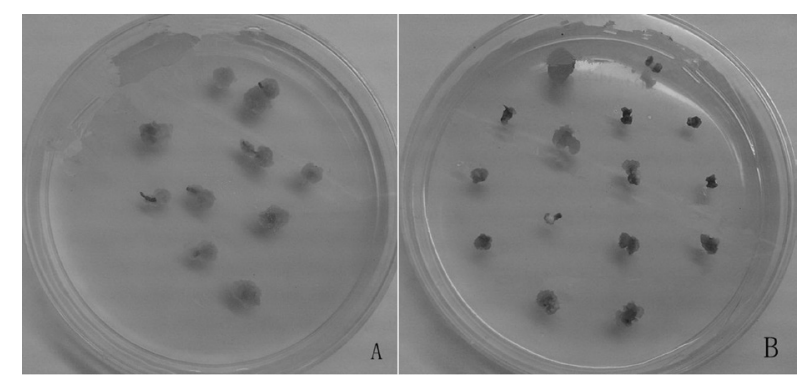

Figure 4. Callus screening. A. Without control of antibiotics. B. Antibiotics screening. 


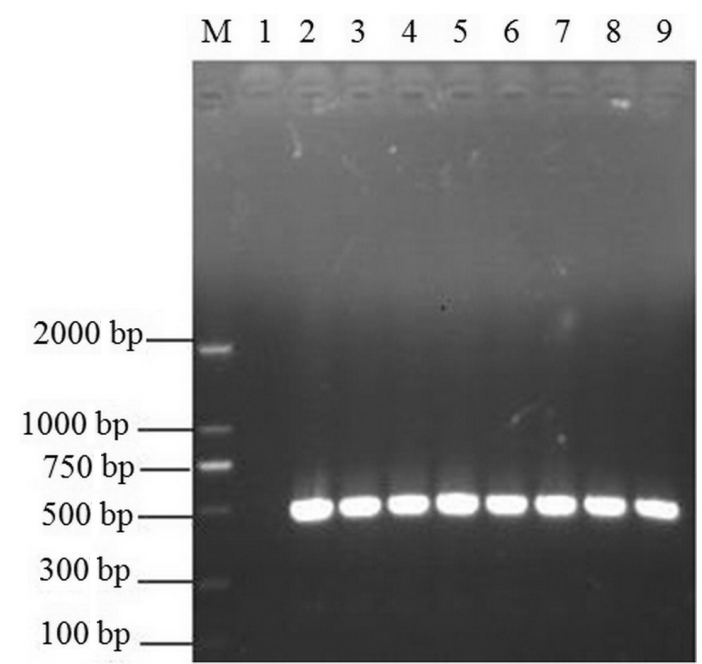

Figure 5. Resistant calluses during PCR detection. Lane $M=$ marker DL2000; lane $1=$ untreated callus; lanes 2 to $9=$ random selection of resistant calluses.

\section{DISCUSSION}

The emergence of the first genetically modified tobacco and the rapid development of transgenic technology have enabled conventional breeding, plant biotechnology, and core improvement of quality. The use of genetically modified technology for improving T. pratense is crucial, given the limited resources of its germplasm and its incompatibility with wild-type germplasms (Khanlou et al., 2011). Local and foreign studies should be more focused on the genetic transformation of $T$. pratense, as it has important application value but has not been thoroughly examined. Jung et al. (2000) transformed the IFS gene into Arabidopsis and soybean and detected $2 \mu \mathrm{g} / \mathrm{g}$ genistein in the leaves and stems (Jung et al., 2000; Maul and Kulling, 2010). The Rhizobia-mediated bean plant transgenic system is highly efficient and involves a simple operation method (Mannella et al., 2012; Yadav et al., 2012; Pandey et al., 2013). The use of the IFS gene in the regulation of isoflavone biosynthesis in the biosynthetic pathway of leguminous styrene acrylic pigments has become a research hotspot (Liu et al., 2007; Shu et al., 2010; Qian et al., 2011). A study examining the roles of Minshan red clover leaf and petiole receptor on IFS in Agrobacterium has prompted further studies on genetic transformation.

In this study, 1575 nucleotides encoding 525 amino acids and 99\% nucleotide homology of the red clover IFS gene were observed based on PCR evaluation of Minshan $T$. pratense callus cloning. The Agrobacterium LBA4404 with pRI101-AN-IFS was co-cultured with explant pre-cultured using the OD600 1.5 Agrobacterium LBA4404 for 3 days, which could effectively transformed neomycin phosphotransferase II and IFS gene into into the $T$. pratense genome. The calluses were obtained after screened under cephalosporin for 3 times. Random PCR tests were conducted on the callus to confirm whether genetic transformation of Minshan T. pratense was successful. This study lays a foundation for future research to improve Minshan T. pratense through genetic engineering. 


\section{ACKNOWLEDGMENTS}

Research supported by 2 grants from the Henan Province Science and Technology Agency in China (\#102102310189 and \#2009A180014).

\section{REFERENCES}

Jung W, Yu O, Lau SM, O’Keefe DP, et al. (2000). Identification and expression of isoflavone synthase, the key enzyme for biosynthesis of isoflavones in legumes. Nat. Biotechnol. 18: 208-212.

Kagan IA and Flythe MD (2012). Factors affecting the separation and bioactivity of red clover (Trifolium pratense) extracts assayed against Clostridium sticklandii, a ruminal hyper ammonia-producing bacterium. Nat. Prod. Commun. 7 : 1605-1608.

Kaurinovic B, Popovic M, Vlaisavljevic S, Schwartsova H, et al. (2012). Antioxidant profile of Trifolium pratense L. Molecules 17: 11156-11172

Khanlou KM, Karimi M, Maroufi A and Van Bockstaele E (2011). Improvement of plant regeneration and Agrobacteriummediated genetic transformation efficiency in red clover (Trifolium pratense L.). Res. J. Biotechnol. 6: 13-21.

Kicel A and Wolbiś M (2013). Phenolic content and DPPH radical scavenging activity of the flowers and leaves of Trifolium repens. Nat. Prod. Commun. 8: 99-102.

Kolodziejczyk-Czepas J (2012). Trifolium species-derived substances and extracts - biological activity and prospects for medicinal applications. J. Ethnopharmacol. 143: 14-23.

Liu CJ, Blount JW, Steele CL and Dixon RA (2002). Bottlenecks for engineering of isoflavone glycoconjugates in Arabidopsis. Proc. Natl. Acad. Sci. U. S. A. 99: 14578-14583.

Liu R, Hu Y, Li J and Lin Z (2007). Production of soybean isoflavone genistein in non-legume plants via genetically modified secondary metabolism pathway. Metab. Eng. 9: 1-7.

Lu XB and Gong ZX (1998). Plant transgenic methods and progress. J. Life Sci. 10: 125-131.

Mannella P, Tosi V, Russo E, Zullino S, et al. (2012). Effects of red clover extracts on breast cancer cell migration and invasion. Gynecol. Endocrinol. 28: 29-33.

Maul R and Kulling SE (2010). Absorption of red clover isoflavones in human subjects: results from a pilot study. Br. $J$. Nutr. 103: 1569-1572.

Overkamp S, Hein F and Barz W (2000). Cloning and characterization of eight P450 cDNAs from chickpea cell suspension cultures. Plant Sci. 155: 101-108.

Pandey S, Mishra A, Patel MK and Jha B (2013). An efficient method for Agrobacterium-mediated genetic transformation and plant regeneration in cumin (Cuminum cyminum L.). Appl. Biochem. Biotechnol. 171: 1-9.

Qian D, Gong D, Jiao L, Zhai Y, et al. (2011). Cloning and expression analysis of key enzymes genes in biosynthesis of soybean isoflavones. Soybean Sci. 30: 743-748.

Reiter E, Gerster P and Jungbauer A (2011). Red clover and soy isoflavones - an in vitro safety assessment. Gynecol. Endocrinol. 27: 1037-1042.

Sabudak T and Guler N (2009). Trifolium L. - a review on its phytochemical and pharmacological profile. Phytother. Res. 23: 439-446.

Shu J, Wei Z and Shu J (2010). Research progress of medicinal plant secondary metabolic engineering. Chemistry 30 : 968-971.

Villaseca P (2012). Non-estrogen conventional and phytochemical treatments for vasomotor symptoms: what needs to be known for practice. Climacteric 15: 115-124.

Wang ZM, Yue MQ, Du WH, Hu LY, et al. (2005). Integrating forage and medicinal value of herding grass rookie a minshan red trilobites. J. Pratacultural Sci. 22: 33-35.

Yadav SK, Katikala S, Yellisetty V, Kannepalle A, et al. (2012). Optimization of Agrobacterium mediated genetic transformation of cotyledonary node explants of Vigna radiata. Springerplus 1: 59. 